\title{
Promoting sustainable waste minimisation in the built environment: a case study of urban housing in Akure, Nigeria
}

\author{
Y. M. D. Adedeji, A. A. Taiwo, G. Fadairo \& O. A. Olotuah \\ Department of Architecture, Federal University of Technology, Nigeria
}

\begin{abstract}
The construction industry is one of the largest solid waste generators all over the globe. Because waste generation from both new construction works, as well as renovation works has been on the increase, it is absolutely necessary for the construction industry to adopt ecologically sound planning and construction practices for the purpose of creating a healthy and sustainable built environment. This is the focus of this paper. It appraises the management of construction waste in Nigeria and Akure in particular. A survey of selected construction sites in Akure is used as a case study to demonstrate the magnitude of poor management level of construction waste generation observed and the implications on the built environment. Research findings reveal that the Ondo State Waste Management Board is responsible for the management of solid waste in the city and over $78 \%$ of the construction waste is disposed indiscriminately or burnt on site, since the mandate of the board does not cover construction waste. Contractors were observed to cart away a sizeable junk of the waste for other uses. The paper suggests a wide range of measures for minimisation of waste on construction sites. These include modularisation of design, standardisation of building components, industrial production of building materials, efficient specification writing, retraining of building professionals, reuse and recycling among others. The paper concludes that there is colossal deficiency in the management of construction waste in the study area and recommend ways of ameliorating it.

Keywords: built environment, construction waste, management, modularisation of design, standard building components, sustainable.
\end{abstract}




\section{Introduction}

Waste generation in building construction and renovation processes is in the increase in many developing nations including Nigeria without commensurate efforts on its management. This waste can be as high as $10-15 \%$ of the materials that goes into a building [1]. DETR [2] reported that a similar large quantum of waste was recorded within the UK, with total construction wastage estimated at around 70 million tonnes per annum. Construction industry is one of the largest solid waste generators, a major consumer of non-renewable resources and is responsible for the emission of almost half of the global greenhouse gases [2]. A recent study in developed countries reveals that $30-40 \%$ of natural resources were exploited by the building industry, 50\% of energy used for heating and cooling in buildings, almost $40 \%$ of global consumption of materials convert to built environment and 30\% of energy used due to housing [3, 4]. The rate of generation of solid waste increases by the day in Nigeria with increase in urban population. An estimated $20 \mathrm{~kg}$ of solid waste is generated per capital per annum in Nigeria, equivalent to 2.2 million tons a year [5, 6].

Waste in the building industry is made up of materials such as wood, laterite, concrete bricks and blocks damaged or unused for various reasons during construction. Others include sand, granite, insulation, nails, electrical wiring, tree stumps as well waste originating from site preparation such digging for foundations or dredging, rubbles, asbestos and other hazardous substances. Studies on waste generation shows that it can arise at any stage of the process, from inception, through to the design, construction and operation of the built facility $[5,7,8]$. These studies have also shown that the 3 most significant sources of construction waste relate to design changes (usually stemming from over-specification, poor detailing, late variations, changing materials previously ordered and alterations to complete work), leftover materials, waste from packaging and non-reclaimable consumables, design/detailing errors, poor storage and handling of materials and insufficient protection of the completed works [9]. Pressures on cost and programme delivery also lead to working practices that are not conducive to conserving materials and avoiding damage [10].

Faniran and Caban [8] noted that levels of waste generated are clearly dependent upon the attitudes of key individuals (in the supply chain) engaged with the project especially the clients, which have the greatest influence over waste issues. This is based on the clients' responsibility to set the environmental standards to which the project team must comply. Besides, professional lapses such as design errors, poor detailing, over-specification, late variations, leftover materials, waste from packaging and non-reclaimable consumables, poor storage and handling of materials are all causes waste generation in the building industry [10]. Conversely, Teo and Loosemore [11] opined that efforts to influence waste management will be less appreciated if those further down the supply chain do not buy-in to more effective waste management practices. It would seem that waste management is often considered a low priority in the strategic planning of projects. Indeed, by the time that construction commences, many of the 
opportunities for waste reduction have already elapsed, with the management team only being able to control waste through reactive management measures.

\section{Waste management and sustainable development}

Sustainability plays a vital role in the development of modern societies. It is an inevitable factor in the enhancement of efficient and strategic development of any society [12]. Consequently, governments and other agencies involved in development s are consciously evolving sustainability in their existing and future vision. Adewole [13] observed that towards the end of the 1980s, there were growing concerns over a radical reappraisal of resource availability and use, the environmental consequences of resource exploitation and the correlation between the environment, poverty and economic change. This re-appraisal has given rise to a new approach to environment and development issues, which seeks to reconcile human needs and the capacity of the environment to cope with the consequences of economic system. This view has been expressed by many researchers on the subject of sustainability. All these hang around the continuous validity of a healthy development that perpetuates a long life status without jeopardising the needs of future generations [2, 3].

It is important to note that there must be a balance between levels of development and the stock of natural resources, that is, development must be at a level that can be sustained without prejudice to the natural environment or to future generations. The construction industry cannot be left out. Therefore, if there is to be sustainable development in waste management in Nigeria, the availability of land (for landfill), human resources, plant and equipment and other tools including capital must be readily available. There is the need to protect future for the next generation by cleaning up the environment of all types of waste, taking into consideration both physical and population development of the state [13]. Hence, waste management must mean the collection, keeping, treatment and disposal of waste in such a way as to render it harmless to human and animal life, the ecology and the environment generally.

\subsection{Waste generation, disposal and management in Akure, Ondo State, Nigeria}

Akure faces daunting environmental problems that are compounded by the daily influx of people in search of a better life, domestic, industrial and construction waste generated daily. These problems include dumping of heterogeneous mass of throw-arrays from residential and commercial and industrial activities, ineffective solid waste management, insufficient sanitary infrastructure; soil, air and water pollution; flooding, ocean surge, insecurity, and limited access to basic infrastructure [5]. The waste generated in Akure can be classified into two namely:

i. Municipal waste (these include domestic and commercial ); and ii. Industrial waste. 


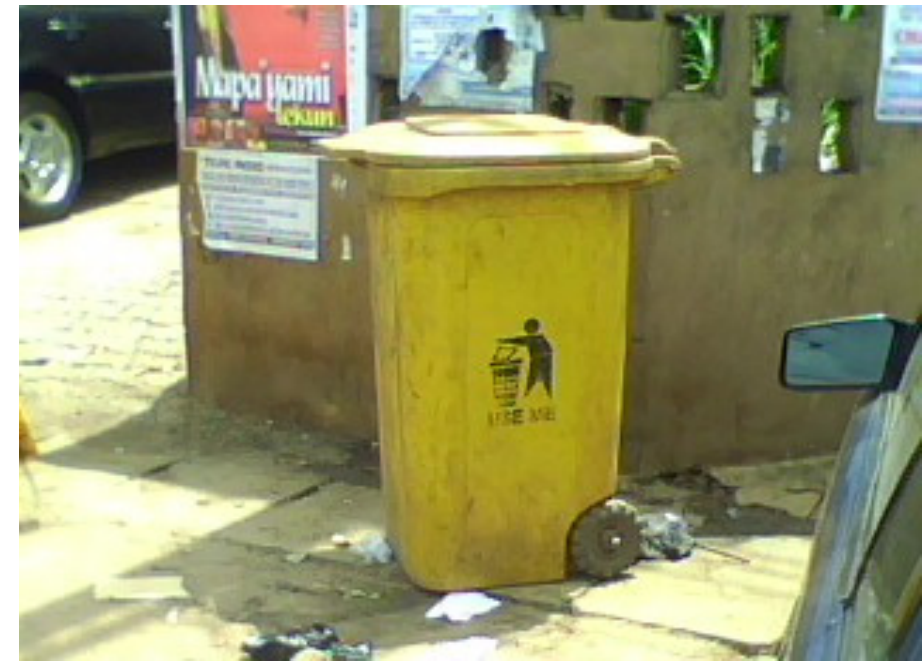

Figure 1: $\quad$ Ondo State government waste bin for waste collection.

\subsection{Ondo state waste management authority}

The agency of government responsible for waste management in Akure is the State Waste Management Authority. It was established on the $23^{\text {rd }}$ April 1999 with the purpose of [5]:

i. enhancing effective waste collection, transportation, disposal and management;

ii. ridding the state (Ondo) of undesirable refuse pilation;

iii. setting guidelines and organizing waste scavenging for recycling;

iv. erasing environmental blightedness and development of epidemic;

v. proffering waste management strategies and turning the state accumulated waste into wealth; and

vi. ensuring a clean and healthy environment.

The Waste Management Authority zoned Akure into ten (10) zones, which were further subdivided into five (5) districts each to facilitate effective discharge of responsibilities [5]. The authority provides dino bins and cat bins to the densely populated areas and commercial centres, while dustbins (drums and buckets) are sold to the less populated areas. Currently, the authority employs two methods of waste collection.

\subsubsection{House-to-house collection}

This method is usually adopted in areas with good road networks within the city capital. This enables easy movement of the waste collection vans. Domestic waste from residential buildings is kept in containers to await removal by the waste collection vans into their refuse side loaders. The type and capacities of the containers used depend on the characteristics of the solid waste to be collected, the frequency of collection and the space available for the placement of the containers. 


\subsubsection{Communal/designated collection}

Solid waste that are generated in offices, commercial and industrial buildings (banks, institutions, hotels) and open spaces including market and religious places are usually collected in relatively large containers known as dino bins or cart wagons. Empty bins are usually kept in open spaces to be filled up by users and thereafter removed by the authority for disposal. The filled containers are removed by means of roll-on-roll-off trucks, emptied and returned to their original location. Records from the authority shows that the bins are collected twice daily in areas where generation is very heavy (such as the market areas). Each dino bin contains 4.6 tons of waste [5].

During peak seasons, when waste generation is higher than usual, pay loaders and open tippers are used to compliment the collecting vans. However, the activities of the Waste Management Authority does not cover construction waste generated at the construction sites as these are left for the discretion of clients and contractors.

\section{Research methodology: case studies}

A survey of selected construction sites in Akure was used as a case study to gather data through observations and photographic prints. Selected cities were purposively chosen as study areas to reflect the magnitude of waste generated from construction processes. Data were collected through visits to selected sites, investigation and observations. Interview schedules prepared in question forms and written in English language were administered to professionals and site supervisors on site by the authors to collect data on the causes of waste observed on sites. Many of the surveyed projects, in various stages of completion were observed to be littered with unused and overused building materials together with others to be disposed after use.

\section{Findings and discussion of results}

Construction waste observed on surveyed sites include wood, bamboo, nails, tree stumps, laterite, sandcrete blocks, concrete bricks and blocks damaged or unused for various reasons during construction. Others include bags of used cement, waste from packaging and non-reclaimable consumables, sand, granite, pieces of roofing sheets, insulation, electrical wiring, as well waste originating from site preparation such digging for foundations or dredging, rubbles, asbestos and other hazardous substances as shown in Figs $2-4$.

Much of this waste, such as sandcrete blocks, granite and interlocking tiles, resulted from over specifation and ordering of materials to sites, late alterations to works and changing materials previously ordered. Others such as planks, bamboos, pieces of roofing sheets, nails were left over and waste from formworks after use. A more rational precision in professional expertise and management of construction projects could reduce such waste to a minimal level. 
Standard materials for formworks that could be dismantled and used in other sites as used in many big construction works should be adopted to avoid waste resulting from formworks.

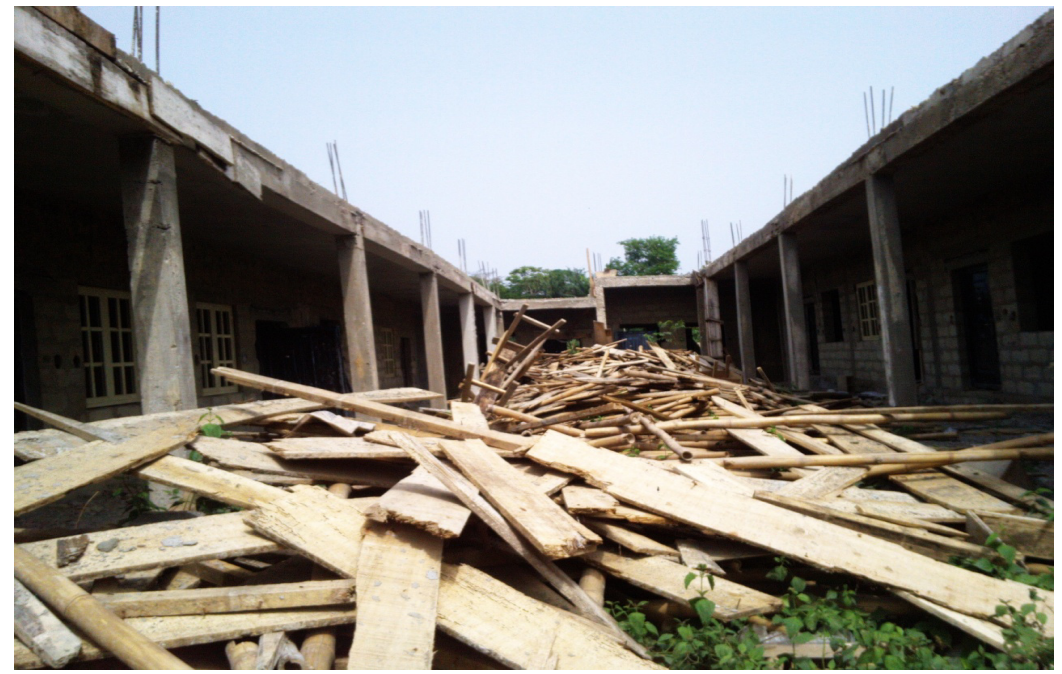

Figure 2: Wood and bamboo used as formwork after use on a construction site.

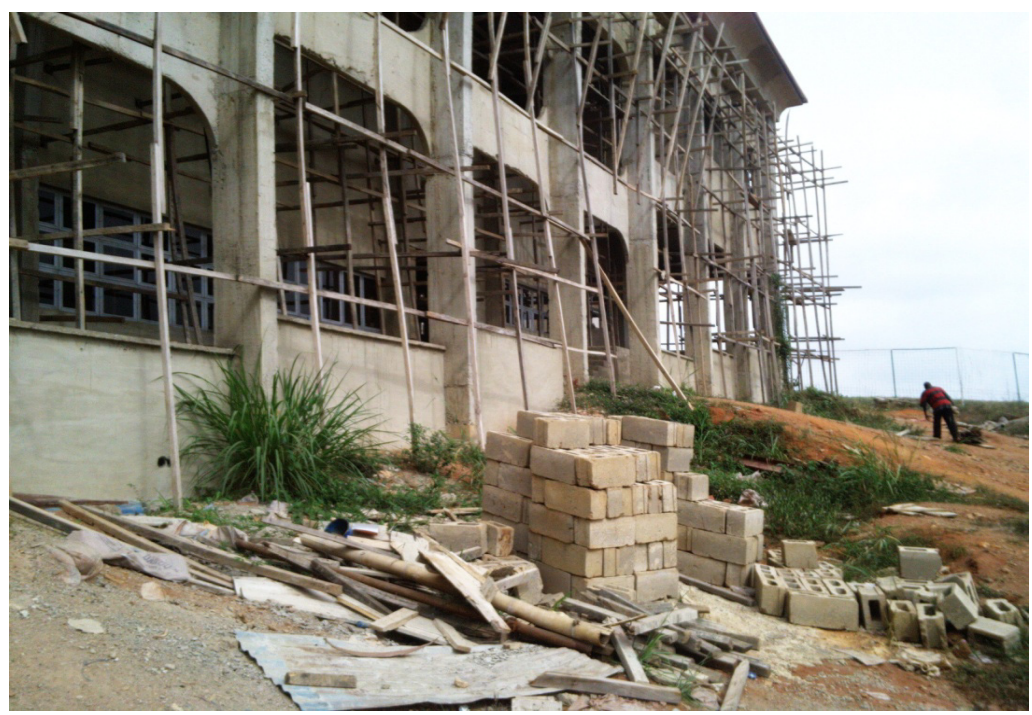

Figure 3: Construction waste: laterite soil from digging, sandcrete blocks, roofing sheets, laterite, bamboo and wood on a construction site. 


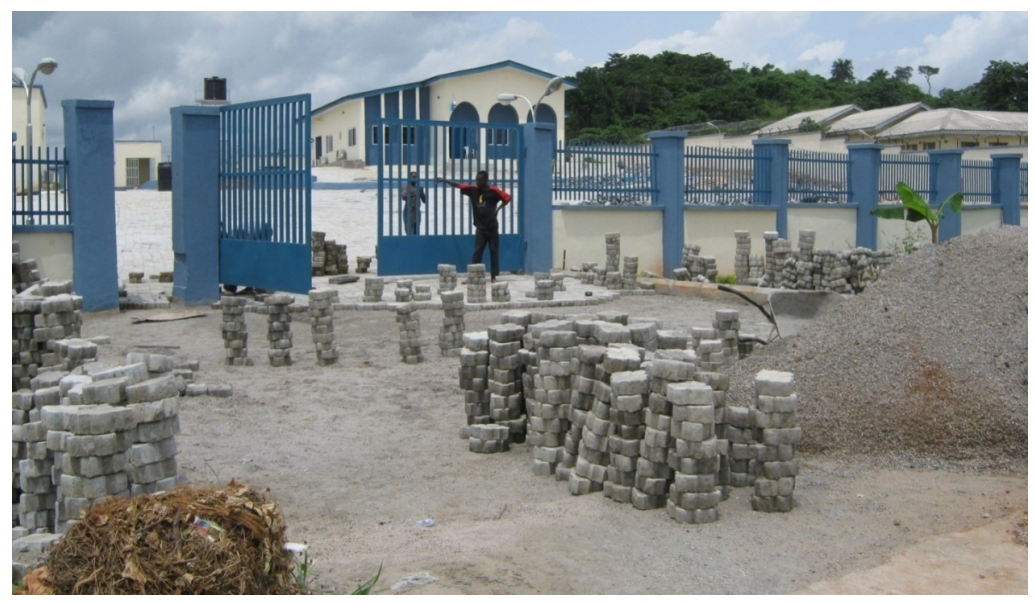

Figure 4: Unused interlocking tiles, granite and refuses on a recently completed building project.

\subsection{Standardisation of design/modular design}

It was observed that the conventional methods of designs and constructions contributed to waste generation on site. Adedeji [14] opined that modular design and standardisation of spaces to improve buildability and reduce the quantity of off-cuts are strategies to significantly reduce construction waste resulting from the conventional methods of designs. By designing spaces and ceiling heights in multiples of standard material and sizes, a substantial reduction in off-cuts would be achieved [10]. Standardization of design and building components should be explored beyond the accessibility to materials only, but the assessment of baseline for the continuous initiatives for designs and intelligent usage of available materials for construction [14].

\subsection{Use of renewable building materials for construction}

In most of the site surveyed, sandcrete blocks were used for masonry works. This material is often associated with off-cuts and enormous waste. Minimisation of waste in masonry works can be achieved by adopting renewable building materials for construction [14]. One of such materials is unfired solid interlocking laterite/clay (Hydraform blocks) [15]. The usage of Hydraform blocks, in place of conventional fired ones, can significantly reduce the energy use and also cut down $\mathrm{CO}_{2}$ emissions and minimize generated waste [16]. Usually, solid laterite blocks are produced on the site where the materials are available. Laterite soil with good grain size distribution and good cohesive performance is a good material for production of interlocking block, but the proportion of clay and aggregates has to be checked [17]. Interlocking blocks are manufactured by hydraulically compressing a soil and cement mixture in a 
block-making machine. Where the material is unused, excess can recycled on site and reused.

The development of interlocking blocks (solid interlocking laterite blocks) shows some merits over the conventional types. First, substantial cost savings can be achieved due to elimination of bedding mortar in the superstructure (except in ring beams and in high gables), thereby reducing workmanship.

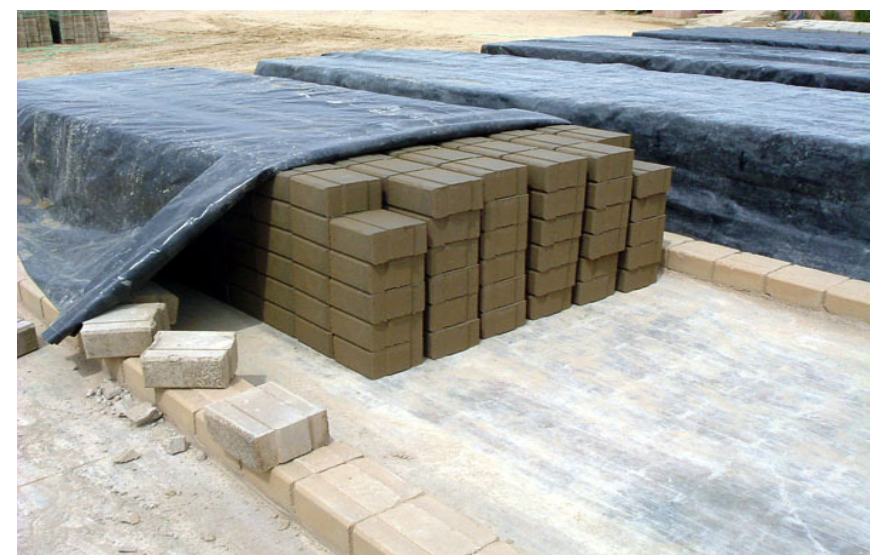

Figure 5: $\quad$ Renewable solid laterite (Hydraform) blocks produced in-situ.

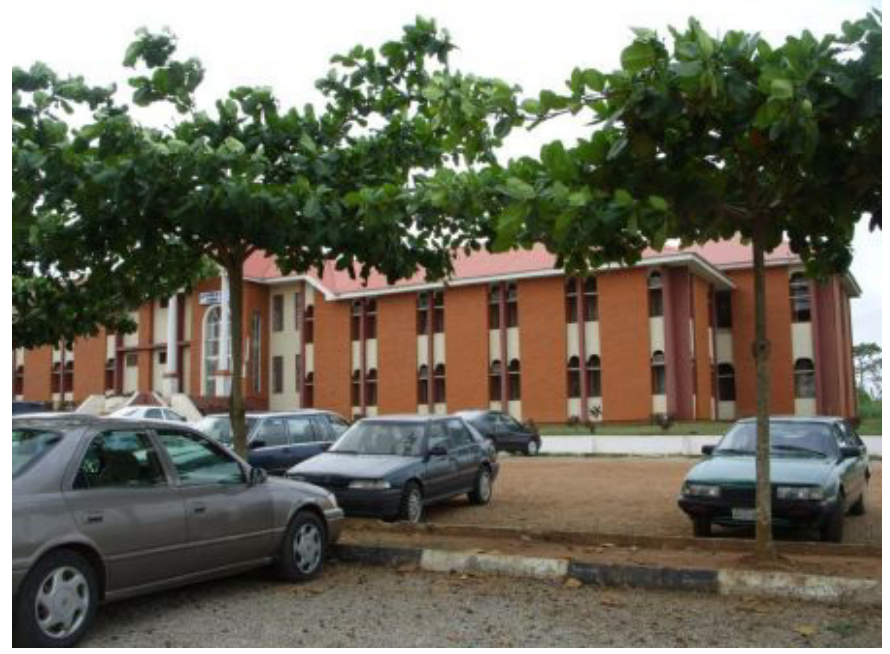

Figure 6: School of Earth and Mineral Sciences, Federal University of Technology, Akure. Use of brick facing as wall finishing

In this system, freely-available subsoil is the main raw material and the blocks do not require costly burning; transport costs are minimised since production of Hydraform blocks takes place on site in hydraulic block machines, 
available from Hydraform International (Pty) Ltd., headquartered in Johannesburg, South Africa. In addition, speed of construction is a valuable feature of the system, which is much faster than other building methods [17].

The main disadvantage of using these products is susceptibility to water damage, which can be avoided by stabilizing the laterite soil with the addition of small quantity of cement or lime.

\subsection{Dry methods construction/use of prefabricated materials}

Off-site prefabrication and industrial production of building materials and components are advocated for in order to minimize waste in the building industry. Prefabrication should be strictly based on designers' specification and standard sizes recommended in the industry. Also, the use of dry construction methods with appropriate standardised components to reflect the designer's specification would reduce or completely eliminate wastages, reduce labour to be engaged, reduce cost as well as the time for construction if the building operation is professionally handled [14]. In view of this, dry construction method is therefore more cost-effective and preferred above the conventional method as confirmed by this research.

Similarly, the application of standardised components has the potential of regularising dimensional units of spaces in a modular form. Professionals and stakeholders in the building industry can easily visualise with clearer perception their proposed building projects, thus, making materials and cost planning easier. Other advantages of the use of prefabricated materials include flexibility of space arrangement, dry construction, industrial production and comparative cost effectiveness.

\subsection{Design management to ensure efficient specification of materials}

Designers and allied building professionals are to ensure accurate dimensions of spaces and building components together with efficient specification of materials for construction in order avoiding over ordering of materials to the site. This will facilitate considerable waste reduction and financial cost savings on projects. Similarly, the engagement experienced project managers for a large scale project is another effective step in ensuring waste reduction. A similar study carried out by Dainty and Brooke [10] made similar observation.

\subsection{Retraining of building personnel}

It is vital for the Nigerian Institute of Architects, Ministry of Housing and Urban Development, and other Institutions and agencies responsible for teaching and training professionals to organise seminars and regular training programmes on effective waste minimization strategies to equip professionals with adequate knowledge on their relevance $[13,18]$. Similar retraining should be extended to workmen on site on the usage of materials towards waste reduction in the building pro. These will not only publicise the contents of this research and other 
related ones but will generate better opportunity to advance the current status of the research in this direction.

\section{Policy implications and recommendations}

The built environment in Nigeria is faced with numerous urban challenges. Similarly, there are problems encountered on construction sites such as overspecification and delivery of materials, leftover materials, waste from packaging and non-reclaimable consumables, poor storage and handling of materials are all causes of waste generation in the building industry. Professionals in the building industry must rise up to these challenges with the adoption of waste minimisation strategies that will enhance sustainability in the sector. These strategies should stem from design stages to the specification of materials and methods of construction to be adopted. Modularisation of designs is strongly advocated for to enhance efficiency in materials specification and reduce off-cuts of materials associated with conventional methods of design and materials usage on building sites. Likewise, prefabricated materials are recommended for finishes and components in buildings as this would substantially minimise waste. The application of standardised components in construction of a building will enhance fast construction operations to be accomplished within couples of hours depending on the magnitude of the building. The policy makers should encourage standardisation of building components in Nigeria in line with the global trend as canvassed by the International Standard Organisation (ISO). This implies that building materials particularly timber and masonry materials should be available in the market in this form for users to purchase in finished forms to be assembled on site. Factories that produce standard components should be established. Besides, the use of renewable materials will enhance recycling of such materials where necessary. Design management towards ensuring efficient specification of building materials and retraining of building professionals and workmen are advocated for as ways of minimising waste in the built environment.

\section{Conclusion}

The focus of this paper is the adoption of ecologically sound planning and construction practices for the purpose of creating a healthy and sustainable built environment. The paper appraises the management of construction waste in Nigeria. A survey of selected construction sites in Akure is used as a case study to demonstrate the magnitude of poor management level of construction waste generation observed and the implications on the built environment. Management of construction waste in Akure, Ondo state, Nigeria (the study area) is highly deficient. Over $78 \%$ of the construction waste is disposed indiscriminately or burnt on site. Contractors cart away a sizeable junk of the waste for other uses. Waste minimisation on construction sites can be achieved through modularisation of design, standardisation of building components, industrial 
production of building materials, efficient specification writing, and retraining of building professionals.

\section{References}

[1] Evia O.W. Wong and Robin C.P. Yip, Promoting sustainable construction waste management in Hong Kong. Construction Management and Economics, As accessed on 4 October 2007, 2004.

[2] Department of the Environment, Transport and the Regions. Guide to Waste Reduction on Construction Sites, DETR, M0007184NP, London, 2000.

[3] Loucks, D.P., Qualifying trends in system sustainability. Hydrological Sciences Journal, 42(4), pp. 513-530, 1997.

[4] Sahley, H.R., Kennedy, C.A., and Adams, B.J., Canadian Journal of Civil Engineering, 32, pp. 72-85, 2005.

[5] Olotuah, A.O., Solid waste management and the built environment: the Nigerian urban housing situation. In: E.H. Chan, and D.C. Ho (Eds.), Proceedings of the CII-HK Conference 2005 on Healthy Building, Community Health and Built Environment, pp. 87-93, November, 2005.

[6] Ogunsote, O.O., Adedeji, Y.M.D. and Prucnal-Ogunsote, B.P., Combating Environmental Degradation through Sustainable Landscaping in Emerging Mega Cities: A Case Study of Lagos, Nigeria. Proceedings of the XXIV World Congress of Architecture, UIA 2011 Tokyo, 2011.

[7] Gavilan, R.M. and Bernold, L.E., Source evaluation of solid waste in building construction, Journal of Construction Engineering and Management, Vol. 120 No. 3, pp. 536-55, 1994.

[8] Faniran, O.O. and Caban, G., Minimising waste on construction project sites, Engineering Construction and Architectural Management 5, Vol. 2, p. 183, 1998.

[9] Dainty, A.R.J. and Brooke, R.J. Towards improved construction waste minimization. Structural Survey, Volume 22, Number 1, 20-29, 2004.

[10] Coventry, S. et al. (2001), Demonstrating Waste Minimisation Benefits in Construction, CIRIA Publication C536, 0-86017-536-7, London.

[11] Teo, M.M.M. and Loosemore, M., A theory of waste behaviour in the construction industry. Construction Management and Economics, Vol. 19 No. 7, pp. 741-51, 2001.

[12] Alsaqqaf, Z. and Zhang, H., Towards a sustainable system: application of temporal analysis on flood risk management. In C.A. Brebbia and E. Beriatos (Eds.), Sustainable Development and Planning V, WIT Press, Ashurst, Southampton, United Kingdom, 59-68, 2011.

[13] Adewole, A.T., Waste management towards sustainable development in Nigeria: A case study of Lagos state. International NGO Journal Vol. 4(4), pp. 173-179, 2009. Available online at http://www.academicjournals.org /INGOJ

[14] Adedeji, Y.M.D., Materials preference options for sustainable low-income housing in selected cities in Nigeria. An unpublished Ph.D Thesis, 
Department of Architecture, Federal University of Technology, Akure, 2007.

[15] Oti, J.E.; Kinuthia, J.M.; Bai, J. Engineering properties of unfired clay masonry bricks. Eng. Geol. 107, 130-139, 2009.

[16] Joseph, P., Sustainable non-metallic building materials. Sustainability Review 2, 400-427, www.mdpi.com/journal/sustainability, 2010.

[17] Adedeji, Y.M.D., Housing economy: use of interlocking masonry for lowcost housing in Nigeria. Journal of Construction Project Management and Innovation, Vol. 1(1): 46-62, 2011.

[18] Adedeji, Y.M.D.; Taiwo, A.A.; Olotuah, A.O. and Fadairo, G., Architectural education and sustainable human habitat in Nigeria. In: C.A. Brebbia and E. Beriatos (Eds.); Sustainability Today, WIT Press, Ashurst, Southampton, United Kingdom, 89-99, 2012. 